\title{
Prospective analysis of 44 consecutive liver transplants performed at a university hospital ${ }^{1}$
}

\author{
Orlando Castro e Silva ${ }^{\mathrm{I}}$, Priscila Nejo"I, Nathalia Cardoso ${ }^{\mathrm{II}}$, Enio David Mente ${ }^{\mathrm{III}}$, Fernanda Fernandes Souza ${ }^{\mathrm{III}}$, Andreza Corrêa \\ Teixeira $^{\mathrm{III}}$, Thiago Freitas ${ }^{\mathrm{IV}}$, Daniel Cagnolati ${ }^{\mathrm{IV}}$ \\ ${ }^{I} \mathrm{PhD}$, Chairman and Head, Department of Surgery and Anatomy, FMRP-USP, Ribeirao Preto-SP, Brazil. Conception and designed of the study, \\ responsible for intellectual and scientific content of the study. \\ IIGraduate student, FMRP-USP, Ribeirao Preto-SP, Brazil. Intellectual, design, scientific content of the study, acquisition of data, manuscript writing. \\ IIIPhD, Unit of Liver Transplantation, Department of Surgery and Anatomy, FMRP-USP, Ribeirao Preto-SP, Brazil. Critical revision.

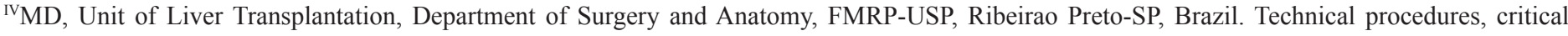 \\ revision.
}

\begin{abstract}
PURPOSE: To analyze the intraoperative and immediate postoperative biochemical parameters of patients submitted to orthotopic liver transplantation.

METHODS: Forty four consecutive orthotopic liver transplants performed from October 2009 to December 2010 were analyzed. The patients (38 male and eight female) were divided into two groups: group A, survivors, and group B, non-survivors. Fifty percent of group A patients were Chid-Pugh C, 40\% Chid-Pugh B and 10\% Chid-Pugh A. In group B, 52\% of the patients were Chid-Pugh C, $41 \%$ Chid-Pugh B, and 17\% Chid-Pugh A. All orthotopic liver transplants were performed by the piggy-back technique without a portacaval shunt in an anhepatic phase. ALT, AST, LDH and lactate levels were determined preoperatively, at five, 60 minutes after arterial revascularization of the graft and 24 and 48 hours after the end of the surgery.( or: after the surgery was finished).

RESULTS: There were no preoperative clinical differences (Child and Meld) between the two groups. The times of warm and hypothermal ischemia were similar for both groups $(p>0.05)$. Serum aminotransferases levels at five and 60 minutes after arterial revascularization of the graft were similar ( $p>0.05)$ for both groups, as also were lactate levels at the time points studied. There was no significant difference in $\Delta$ lactate between groups at any time point studied $(\mathrm{p}>0.05)$. No significant difference was observed between groups during the first 24 and 48 hours after surgery ( $p>0.05$ ).

CONCLUSION: No significant difference in any of the parameters studied was observed between groups. Under the conditions of the present study and considering the parameters evaluated, no direct relationship was detected between the intraoperative situation and the type of evolution of the patients of the two groups studied.
\end{abstract}

Key words: Liver. Liver Transplantation. Aspartate Aminotransferases. Alanine Transaminase. 


\section{Introduction}

The survival rate of patients undergoing orthotopic liver transplantation (OLT) depends on a series of factors in addition to the previous clinical condition of the donor and to the quality of his maintenance in the intensive care unit until the time for surgery to obtain the liver ${ }^{1}$. The characteristics of the transplant candidate, the surgical technique, the quality of liver graft preservation after different periods of hypothermal and normothermal ischemia and anhepatic periods, intensity of the ischemia and reperfusion (I/R) injury with varied clinical repercussions, and also the immediate postoperative care are extremely important and influence the rate of postoperative survival ${ }^{1-2}$.

Because the set of procedures in OLT is highly complex, demanding a multidisciplinary approach, it is important to look for factors that may determine or interfere with the postoperative outcome of patients submitted to OLT ${ }^{1}$. Various studies have been performed in an attempt to find the ideal prognostic index that employs clinical symptoms or comorbidities and accurately predicts which patient is more susceptible to developing postoperative complications that would imply an early mortality (up to 30 days) ${ }^{1-3}$. The aminotransferases (ALT and AST) and lactic dehydrogenase (LDH) are enzymes whose increased serum levels indicate acute hepatocellular suffering with high sensitivity ${ }^{4}$. The Model for End-Stage Liver Disease (MELD) score has the advantage over the traditional Child-Pugh score of being based on objective and readily available variables (serum bilirubin, international normalized ratio of prothrombin time [INR], and serum creatinine) rather than on subjective assessment of degree of clinical abnormalities without universally accepted definitions, and thus widely variable ${ }^{5}$.

The hepatic tissue has a great capability to convert lactate to pyruvate through $\mathrm{LDH}$ and then to glycogen ${ }^{6}$. Consequently, the impairment of liver function after the graft transplantation provoked by systemic hypoperfusion, hypoxia and acidosis is responsible for a low clearance of lactate, especially after reperfusion of the liver? Additionally, all the related clinical factors of both the donor and the recipient and the surgical times of the recipient, especially the times of hypo and normothermal ischemia, are known to interfere directly or indirectly with the degree of I/R injury to the liver during transplantation and to affect the outcome of transplanted patients in a significant manner . $^{8}$

Thus, the objective of the present study was to evaluate the biochemical indicators of a consecutive series of patients submitted to OLT that might be discriminatory regarding early mortality (up to 30 posttransplantation days).

\section{Methods}

Forty four consecutive orthotopic liver transplants performed from October 2009 to December 2010 were analyzed. The patients (36 male and eight female) were divided into two groups: group A, survivors, and group B, non-survivors. Fifty percent of group A patients were MELD C, 40\% MELD B and $10 \%$ MELD A. In group B, 52\% of the patients were MELD C, 41\% MELD B, and 17\% MELD A. All orthotopic liver transplants were performed by the piggy-back technique without a portacaval shunt in an anhepatic phase ${ }^{9}$. ALT, AST, LDH and lactate levels were determined preoperatively and at five and 60 minutes after arterial revascularization of the graft. The patients were evaluated during the first 48 hours after surgery.

\section{Results}

There were no preoperative clinical differences (Child and MELD) between the two study groups. The times of warm and hypothermal ischemia were similar for both groups ( $p>0.05$ ), Table 1. Serum ALT, AST and LDH levels at five and 60 minutes after arterial revascularization of the grafts were similar $(p>0.05)$ for both groups, as also were lactate levels at the time points studied. There was no significant difference in $\Delta$ lactate between groups at any time point studied $(\mathrm{p}>0.05)$. No significant difference was observed between groups during the first 24 and 48 hours after surgery $(\mathrm{p}>0.05)$, Tables 2 and 3 .

TABLE 1 - Gender, age, Child, MELD and time of hypothermic and warm ischemia of transplanted patients.

\begin{tabular}{ccc}
\hline $\begin{array}{c}\text { Patients } \\
(\mathrm{n}=44)\end{array}$ & $\begin{array}{c}\text { Survivors } \\
(\mathrm{n}=30)\end{array}$ & $\begin{array}{c}\text { Non-Survivors } \\
(\mathrm{n}=14)\end{array}$ \\
\hline $\begin{array}{c}\text { Gender } \mathbf{M} / \mathbf{F} \\
\text { *Age }\end{array}$ & $27 / 3$ & $9 / 5$ \\
Child A & $46 \pm 13$ & $51 \pm 9$ \\
Child B & 12 & 20 \\
Child C & 44 & 40 \\
& 44 & 40 \\
MELD & 16 a 60 & $14 \mathrm{a} 40$ \\
*Time of hypothermal & $8.16 \pm 1.65$ & $7.98 \pm 0.86$ \\
Ischemia (hours) & & \\
*Time of warm & $64.56 \pm 30.35$ & $63.2 \pm 74.7$ \\
Ischemia (minutes) & &
\end{tabular}

*Values expressed as mean $\pm \mathrm{SD}$ 
TABLE 2 - Time of post-graft revascularization and ALT, AST, LDH and $\Delta$ lactate levels of survivor patients.

\begin{tabular}{ccccc}
\hline Group & \multicolumn{4}{c}{ Survivors (A) } \\
\hline $\begin{array}{c}\text { Time Post Graft } \\
\text { Revascularization }\end{array}$ & $5 \mathrm{~min}$ & $60 \mathrm{~min}$ & $24 \mathrm{~h}$ & $48 \mathrm{~h}$ \\
& & & & \\
ALT (U/L) & $410 \pm 74$ & $647 \pm 599$ & $915 \pm 203$ & $783 \pm 146$ \\
AST (U/L) & $659 \pm 116$ & $1.016 \pm 910$ & $1.348 \pm 363$ & $1.580 \pm 395$ \\
LDH (U/L) & $2.080 \pm 364$ & $3.049 \pm 2,863$ & $3.105 \pm 600$ & $2.700 \pm 500$ \\
$\Delta$ Lactate & $-0.9 \pm 0.3$ & $3.1 \pm 0.6$ & $+1.2 \pm 1.0$ & $-0.7 \pm 0.2$ \\
\hline
\end{tabular}

*Values expressed as mean $\pm \mathrm{SD}$

TABLE 3 - Time of post-graft revascularization and ALT, AST, LDH and $\Delta$ lactate levels of non-survivor patients.

\begin{tabular}{ccccc}
\hline Group & \multicolumn{4}{c}{ Non-Survivors (B) } \\
\hline $\begin{array}{c}\text { Time Post Graft } \\
\text { Revascularization }\end{array}$ & $5 \mathrm{~min}$ & $60 \mathrm{~min}$ & $24 \mathrm{~h}$ & $48 \mathrm{~h}$ \\
& & & & \\
*ALT & $346 \pm 69$ & $655 \pm 735$ & $1.330 \pm 878$ & $938 \pm 605$ \\
*AST & $569 \pm 130$ & $1.077 \pm 819$ & $1.600 \pm 500$ & $1.606 \pm 550$ \\
*LDH & $2.011 \pm 421$ & $2.974 \pm 2.622$ & $2.823 \pm 1.886$ & $2.600 \pm 510$ \\
$\Delta$ Lactate & $-1.2 \pm 0.5$ & $4.2 \pm 2.0$ & $+2.0 \pm 1.5$ & $+1.2 \pm 0.8$ \\
\hline
\end{tabular}

*Values expressed as mean $\pm \mathrm{SD}$

\section{Discussion}

Several literature reports have shown the constant search for indicators that might predict with high sensitivity the type of outcome of patients submitted to OLT ${ }^{10-11}$.

The mathematical index MELD, published in $2002^{12}$ in the United States and adopted in Brazil in $2006^{13}$, has been preferentially used as an index for allocation of organs for transplantation. However, as an indicator of the severity of liver disease and as a predictive factor of the type of patient outcome after surgery (survival and mortality), it has not proved to be sensitive enough to discriminate between post-OLT survivors and non-survivors.

The aminotransferases ALT and AST and $\mathrm{LDH}^{4}$, sensitive markers of acute hepatocellular injury, have proved to be sensitive in indicating different levels of (I/R injury, although they do not demonstrate significant differences in the type of outcome of transplanted patients ${ }^{14}$. In the present investigation, no statistically significant difference was detected in the levels of these enzymes between the two types of outcome studied.

During liver transplantation the tissue injury occurs as a result of the initial ischemic insult, which is determined primarily by the magnitude and duration of the subsequent damage induced by reperfusion ${ }^{7}$. As a consequence, serum lactate level increases and may be used as a sensitive indicator both of the hepatocellular injury caused by I/R and eventually of postoperative outcome. It is known that, under conditions of reduced hepatic flow, there is an increase in serum lactate, which may then function as an indicator of liver injury, even though temporary ${ }^{7}$. On this basis, it would be expected that, the higher the I/R injury, the higher the serum lactate levels, or vice versa. Thus, we may assume that serum lactate may function separately as a predictive index of the type of outcome of patients after OLT. As shown in Table 1, the normal and hypothermal times of ischemia were similar for both groups.

In the present study, we expressed the behavior of serum lactate as the difference $(\Delta)$ between its postoperative and preoperative values. Analysis of the results showed that serum lactate did not prove to be a sensitive indicator of the type of postoperative outcome. Other studies are needed in order to continue to look for indicators that might predict the type of outcome of patients submitted to complex procedures involving multiple risk factors such as liver transplantation.

\section{Conclusion}

No significant difference in any of the parameters studied was observed between groups. Under the conditions of the present study and considering the parameters evaluated, no direct relationship was detected between the intraoperative situation and the type of evolution of the patients of the two groups studied.

\section{References}

1. Cywinski JB, Mascha EJ, You J, Sessler DI, Kapural L, Argalious M, Parker BM. Pre-transplant MELD and sodium MELD scores are poor predictors of graft failure and mortality after liver transplantation. Hepatol Int. 2011;5:841-9.

2. Castro-E-Silva O, Sankarankutty AK, Teixeira AC, Mente ED, Souza FF, Pacheco EG, Oliveira GR, Cagnolatti D, Correia RB, Campos W, Kemp R, Miranda A, Rondon LZ, Rizzo C, Mota GA, Martinelli AL, Ramalho FS, Ramalho LN, Zucoloto S. Liver transplantation at a university hospital, faculty of the medicine of Ribeirão Preto, University of São Paulo: results for the first 60 Recipients. Transplant Proc. 2008;40:785-8.

3. Sharma P, Schaubel DE, Sima CS, Merion RM, Lok AS. Reweighting the model for end-stage liver disease score components. Gastroenterology. 2008;135:1575-81.

4. Giannini EG, Testa R, Savarino V. Liver enzyme alteration: a guide for clinicians. CMAJ. 2005;172:367-79.

5. Salerno F, Merli M, Cazzaniga M, Valeriano V, Rossi P, Lovaria 
A, Meregaglia D, Nicolini A, Lubatti L, Riggio O. MELD score is better than Child-Pugh score in predicting 3-month survival of patients undergoing transjugular intrahepatic portosystemic shunt. J Hepatol. 2002;36:494-500.

6. Luft FC. Lactic acidosis update for critical care clinicians. J Am Soc Nephrol. 2001;12(Suppl 17):S15-9.

7. Basile-Filho A, Nicolini EA, Auxiliadora-Martins M, Silva Jr Ode C. The use of perioperative serial blood lactate levels, the APACHE II and the postoperative MELD as predictors of early mortality after liver transplantation. Acta Cir Bras. 2011;26:535-40.

8. Piratvisuth T, Tredger JM, Hayllar KA, Williams R. Contribution of true cold and rewarming ischemia times to factors determining outcome after orthotopic liver transplantation. Liver Transplant Surg. 1995;1:296-301.

9. Tzakis A, Todo S, Starzl TW. Orthotopic liver transplantation with preservation of the inferior vena cava. Ann Surg. 1989;210:649-52.

10. Basile-Filho A, Nicolini EA, Auxiliadora-Martins M, AlkmimTeixeira GC, Martinez EZ, Martins-Filho OA, de Castro e Silva O. Comparison of acute physiology and chronic health evaluation II death risk, Child-Pugh, Charlson, and model for end-stage liver disease indexes to predict early mortality after liver transplantation. Transplant Proc. 2011;43:1660-4.

11. Thuluvath PJ, Yoo HY, Thompson RE. A model to predict survival at one month, one year, and five years after liver transplantation based on pretransplant clinical characteristics. Liver Transplant. 2003;9:527-32.

12. Freeman RB. MELD: the holy grail of organ allocation? J Hepatol. 2005;42:16-20.

13. Teixeira AC, Souza FF, Mota GA, Martinelli AL, Sankarankutty AK, Silva OC. Liver transplantation: expectation with MELD score for liver allocation in Brazil. Acta Cir Bras. 2006;21(Suppl.1):12-4.

14. Lombardi AC, Mente ED, Sankarankutty AK, Souza FF, Teixeira AC, Cagnolati D, Souza ME, Silva Jr OC. Analysis of 83 consecutive liver transplants performed at a tertiary care reference hospital in the interior of the state of Sao Paulo. Acta Cir Bras. 2011;26:530-4

\section{Correspondence:}

Orlando de Castro e Silva

Hospital das Clínicas de Ribeirão Preto

Departamento de Cirurgia e Anatomia

Av. Bandeirantes, $3900 / 9^{\circ}$ andar

14048-900 Ribeirão Preto - SP Brasil

orlando@ffmrp.usp.br

Received: August 20, 2012

Review: October 22, 2012

Accepted: November 23, 2012

Conflict of interest: none

Financial sources: Sao Paulo Research Foundation (FAPESP) and Council of Technological and Scientific Development (CNPq)

${ }^{1}$ Research performed at Unit of Liver Transplantation, Department of Surgery and Anatomy, Faculty of Medicine of Ribeirao Preto, University of Sao Paulo (FMRP-USP), Ribeirao Preto-SP, Brazil. 